末廣 栄一, 小泉 博靖, 井上 貴雄, 藤山 雄一, 篠山 瑞也, 出口 誠, 米田 浩,

石原 秀行, 野村 貞宏, 鈴木 倫保

山口大学医学部脳神経外科

\title{
Neurocritical Care for Traumatic Brain Injury
}

Eiichi Suehiro, M.D., Ph.D., Hiroyasu Koizumi, M.D., Ph.D., Takao Inoue, Ph.D., Yuichi Fujiyama, M.D., Mizuya Shinoyama, M.D., Ph.D., Makoto Ideguchi, M.D., Ph.D., Hiroshi Yoneda, M.D., Ph.D., Hideyuki Ishihara, M.D., Ph.D., Sadahiro Nomura, M.D., Ph.D., and Michiyasu Suzuki, M.D., Ph.D.

Department of Neurosurgery, Yamaguchi University School of Medicine

In Japan, there has been a decrease in head injuries due to traffic accidents, but an increase in these injuries in the elderly due to a fall or a slip. This increase is associated with the rapid aging of society. Thus, diffuse brain injury has decreased, while focal brain injury has increased.

More effective surgical interventions have reduced mortality, but other outcomes have not changed. Intracranial pressure (ICP) monitoring is required in intensive treatment of severe head injury, but the Japan Neurotrauma Data Bank showed a reduced rate of ICP monitoring from $36.0 \%$ of cases in 1998 to $28.0 \%$ in 2009. Patients who underwent ICP monitoring tended to be younger and had cerebral edema based on head CT. Good outcomes were significantly more common in patients with an ICP $\leq 20 \mathrm{mmHg}$, whereas mortality was significantly higher in patients with an ICP $>40 \mathrm{mmHg}$. Procedures for ICP monitoring varied in terms of measurement sites and devices. The normal recommendation is to measure ICP using a ventricular catheter, but ICP in Japan is more frequently measured in the brain parenchyma, followed by the subdural space and ventricle.

Treatment of intracranial hypertension starts with noninvasive pharmacotherapy. Decompressive craniectomy is used as the final option. The Japan Neurotrauma Data Bank showed that these therapies were used in patients who underwent ICP monitoring and led to a significant decrease in mortality, but did not improve functional outcomes. A mutual understanding of treatment policies between neurosurgeons and neurointensivists leading to an integrated therapeutic approach is likely to improve the treatment outcomes of head injury.

(Received August 18, 2015 ; accepted September 29, 2015)

Key words : traumatic brain injury, neurocritical care, intracranial pressure monitoring, the Japan Neurotrauma Data Bank

Jpn J Neurosurg（Tokyo）25:214-219, 2016 


\section{日本の頭部外傷の現状}

日本における頭部外傷の疫学研究は, 1990 年代初めよ り地域の頭部外傷データバンクの設立により開始され $た^{6) 12)}$. 全国的な調査は, 1998 年より日本神経外傷学会 の事業として，日本頭部外傷データバンクが開始され た。これまでにプロジェクト 1998 (P1998), P2004, $\mathrm{P} 2009$ の 3 つの大規模疫学研究が施行され, 2015 年 4 月 より P2015が開始されている。これまでの 3 つの大規模 疫学研究の結果をもとに, 日本の頭部外傷の現状につい て述べたい.

近年の頭部外傷患者の年齢分布は, 日本社会の高齢化 とともに推移している.P1998での全登録患者の平均年 齢は 47.4 歳であったが, P2009では 57.0 歳と 1 歳/年の 割合で上昇している7)。 また, 年齢別発生頻度をみると, P1998 では若年者層と高齢者層にピークを認める二峰性 であったが，近年では若年者層の減少と高齢者層の増加 により，60〜84 歳の高齢者層にピークを認める単峰性と なっている7).

以前は，頭部外傷の受傷機転としては交通外傷が最多 であった。しかし，近年は若年者層における交通事故の 減少と高齢者層における転倒の増加に伴い，P2009 では 転倒・転落が頭部外傷の受傷機転として最多となった ${ }^{7}$.

入院時の頭部 CT 所見による病態を検討すると, P2009

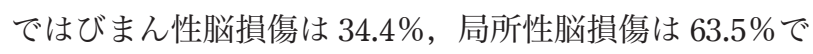
あった. P1998 と比較するとびまん性脳損傷の割合は減 少し, 局所性脳損傷の割合が増加しており, 高齢者層の 転倒による脳挫傷・急性硬膜下血腫の増加を反映してい $3^{7)}$.

P2009における退院時の Glasgow Outcome Scale(GOS) を用いて転帰の評価を行った。転帰良好率（good recovery, moderate disability）は $21.5 \%$, mortality は 45.4\%で あった ${ }^{7)}$. P1998 と比較すると, mortality は有意に減少 しているが，転帰良好率の割合は変化なくvegetative stateが増加していた7).

\section{日本の頭部外傷治療の現状}

\section{1 頭蓋内圧モニターの適応}

頭部外傷集中治療の目的は, 頭部外傷後の二次性脳損 傷を可及的に抑制することである。鎮静薬や高浸透圧利 尿薬の使用，呼吸管理，適切な頭位の維持，脳温管理な ぞを駆使して頭蓋内圧の管理を行い, 適切な脳灌流圧/ 脳血流を維持することで二次性脳損傷を抑制することが できる。この際，頭蓋内圧の連続モニターを観察しなが らの全身管理は必須である。また，意識障害や鎮静薬の 使用により神経学的所見の観察が困難である場合や，多 発外傷・全身循環が不安定であり頻回の CT 撮影が困難 である場合は，頭蓋内の急激な変化を迅速に察知するこ とが困難である，そのような頭蓋内の変化に対応するた めにも頭蓋内圧モニターは必要といえる。

重症頭部外傷治療・管理のガイドライン ${ }^{10)}$ では, 頭蓋 内圧モニターの適応を以下のように提唱している。 (1) Glasgow Coma Scale（GCS） スコア8 点以下, (2)低血圧 (収縮期血圧 $<90 \mathrm{mmHg}$ ), (3) CT 所見 : 正中偏位, 脳槽の 消失などがみられる場合，などが定義されている．

P2009 のデータをみると, 頭蓋内圧を測定している群 〔ICP (+) 群〕は $28.0 \%$, 頭蓋内圧を測定していない群 〔ICP (-) 群〕は 72.0\%であった。 P1998では頭蓋内圧 モニターの施行率は $36.0 \%$ であり，やや減少している. 平均年齢は, ICP (-) 群で $57.1 \pm 24.3$ 歳に対して ICP (+)群で $51.5 \pm 23.5$ 歳と有意に若年であった (Table 1). 入院時の GCS スコアは ICP $(+)$ 群で $7.24 \pm 3.69$, ICP (一) 群で $7.19 \pm 4.02$ で両群間に有意差はなかった (Table 1)。また，低血圧（収縮期血圧 $<90 \mathrm{mmHg}$ ）の頻度は, ICP (+) 群で 5.5\%, ICP (-) 群で 17.0\%であり（Fig. 1), 低血圧に対して積極的に頭蓋内圧モニターを施行し ているわけではないようである。 入院時の頭部 CT 所見 にて, 中脳周囲槽の圧迫や消失，あるいは $5 \mathrm{~mm}$ 以上の 正中偏位を認める割合がそれぞれ, ICP (-)群で $57.3 \% /$ $34.2 \%$ であのに対して, ICP $(+)$ 群では 69.8\%/42.0\% と有意に高く (Fig. 2, 3), 頭部 CT に拈ける脳浮腫の所

Table 1 Patient characteristics with ICP monitor or not

\begin{tabular}{l|c|c|c}
\hline & ICP monitor (+) & ICP monitor (-) & p value \\
\hline Age (y. o.) & $51.5 \pm 23.5$ & $57.1 \pm 24.3$ & 0.001 \\
GCS & $7.24 \pm 3.69$ & $7.19 \pm 4.02$ & 0.867 \\
Pupillary abnormality (\%) & 40.0 & 44.1 & 0.201 \\
ISS & $27.3 \pm 11.8$ & $28.4 \pm 16.5$ & 0.230 \\
Period of hospital stay (day) & $42.6 \pm 42.4$ & $25.4 \pm 38.8$ & $<0.001$ \\
\hline
\end{tabular}

ICP : intracranial pressure, GCS : Glasgow Coma Scale, ISS : Injury Severity Score 


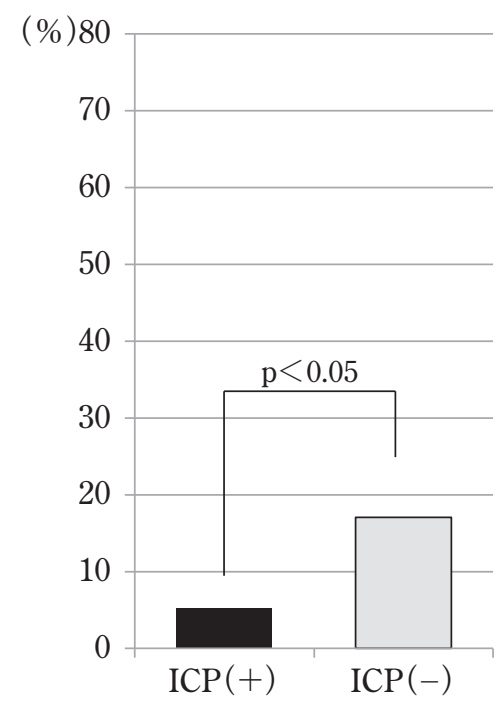

Fig. 1 The rate of patients with hypotension $(<$ $90 \mathrm{mmHg}$ ) on admission

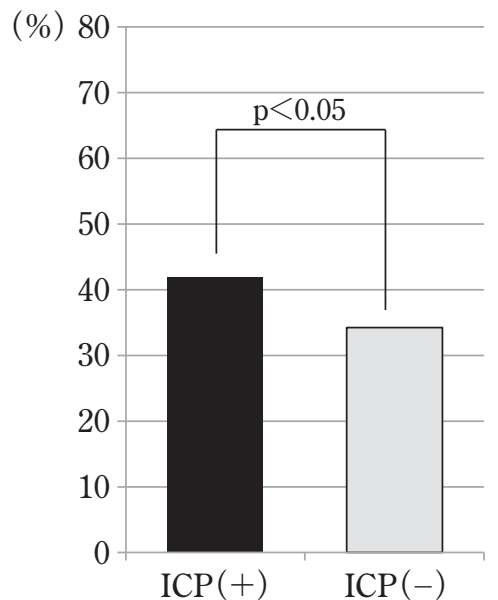

Fig. 3 The rate of patients with midline shift ( $>$ $5 \mathrm{~mm}$ ) on initial CT

見が，頭蓋内圧モニター施行に大きく影響しているよう である。

\section{2 頭蓋内圧の管理目標}

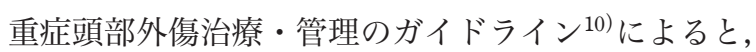
頭蓋内圧の治療を開始する閾值は 15 25 mmHg 程度と されている。 また，小児ではさらに低いレベル（<10 $\mathrm{mmHg}$ )を目標にしたほうがよいとの報告もある ${ }^{10)}$.こ れらの閾值は既存のエビデンスをもとに設定されてい る. Juul $ら^{5)}$ は，頭蓋内圧方進 $(20 \mathrm{mmHg}$ 以上）が神経 学的増悪の予測因子として強く関与していると報告して いる．また，頭蓋内圧の最高值の検討では，成人・小児 ともに 35 40 mmHg が予後を左右する間值であるとさ

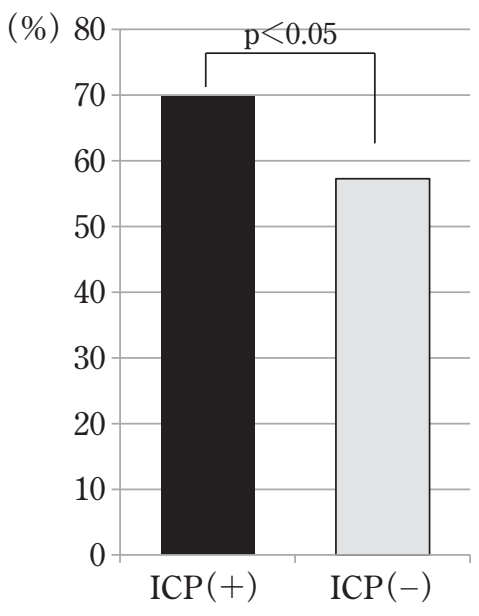

Fig. 2 The rate of patients with perimesencephalic cistern disappearance on initial CT

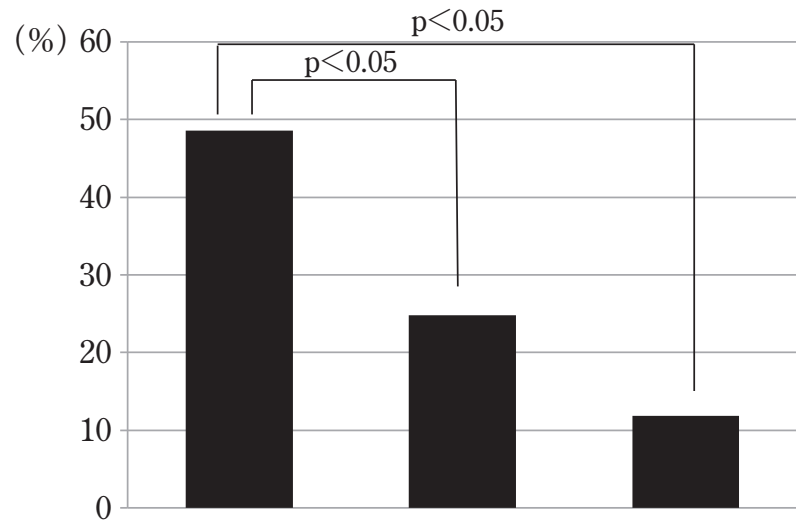

$\sim 20 \mathrm{mmHg} \quad 21 \sim 39 \mathrm{mmHg} \quad 40 \mathrm{mmHg} \sim$

Fig. 4 Favorable outcome rate depends on the maximum ICP value during the measurement period

れている(2)11.

P2009 のデータから，同様の検討を行ってみる．経過 中の頭蓋内圧の最高值が，(1)〜20 mmHg，(2)21〜39 $\mathrm{mmHg}$ ，(3) $40 \mathrm{mmHg} \sim の 3$ 群に分けて，それぞれ転帰良 好率と死亡率を検討した。転帰良好率は，(1)群で $48.6 \%$ に対して，(2)群で 24.8\%，(3)群で 11.9\% と有意に減少し ている (Fig. 4)。死亡率は, (1)群で 12.4\%，(2)群で 21.2\% であったが, (3)群にて 73.8\% と有意に上昇した（Fig. 5). つまり，機能予後を維持するためには頭蓋内压を 20 $\mathrm{mmHg}$ 以下に維持することは重要であり, 頭蓋内圧が 40 mmHg を超えるようであれば, 救命すら困難であること がわかる。 


\section{3 頭蓋内圧モニターの方法}

頭蓋内圧モニターの方法としては，さまざまな測定部 位あるいはデバイスがある。それぞれの利点，欠点を熟 知し，その病態に即した方法を選択しなければならな い. 各種ガイドラインにて, 最も推奨されているのは脳 室内カテーテルからの測定である ${ }^{110)}$. 值の信頼性は最 も高く, 安価であり, 䯣液ドレナージとしても使用可能 である. 感染が $10 \sim 17 \%$, 脳出血が $1.1 \%$, 機能不全が $6.3 \%$ の割合で認められる ${ }^{1)}$. その他の方法として值の信 頼性は低下するが，脳実質内や硬膜下腔の圧を測定する こともある．合併症の頻度は，それぞれ感染が $14 \% /$

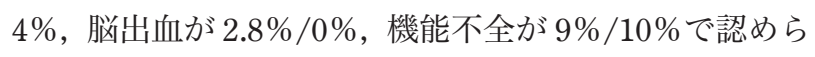
れる1).

特に頭部外傷においては，脳室の圧迫や偏位により脳 室内カテーテルの挿入が困難なことが多い。そのような 場合は，頭蓋内圧モニターのデバイスとして catheter tip transducerが使用される.しかし, catheter tip transducer 挿入中はキャリブレーションができないという欠点があ る.

日本では, 脳実質内への挿入が $67.5 \%$ と最も多く, 硬 膜下腔 $(21.0 \%)$, 脳室内 $(9.8 \%)$, 硬膜外腔 $(1.3 \%)$ と 続いている.

\section{4 頭蓋内圧方進に対する治療}

頭蓋内圧方進を検知できずに治療を㤐ると, 脳へルニ アを起こしてしまい, 不可逆性の大きな脳損傷を生じて しまう。頭蓋内圧充進に対する治療は，一般的に非侵襲 的な治療法から段階的に行われる.

第 1 段階としては，鎮静・鎮痛・呼吸管理である。鎮 静薬はプロポフォールが頭蓋内圧管理を容易にするとの 報告があり ${ }^{8)}$, 米国の重症頭部外傷管理のガイドライン でも推奨されている ${ }^{1)}$. 呼吸管理にて, 少なくとも高二 酸化炭素血症は避けるべきである。頭蓋内圧光進時に は, $\mathrm{PaCO}_{2}$ の目標を 30〜 $35 \mathrm{mmHg}$ として過換気療法を行 うが, 頚静脈球酸素飽和度や脳組織酸素分圧などのモ二 タリングを行いながら, 短期間で使用することが推奨さ れている ${ }^{10)}$.

次の段階として，頭部挙上が有用である。頭位につい ては 30 度が推奨されているが ${ }^{10)}$, 頚部の屈曲は静脈灌流 を障害し頭蓋内圧を上昇させるので注意が必要である。

浸透圧療法は, 血液脳関門内外での浸透圧勾配を用い て間質の水分を血管内に引き込むことで頭蓋内圧を下げ る方法である。日本ではグリセロールが多用されている が，海外ではマンニトールや高張食塩水が多く使われて いる.

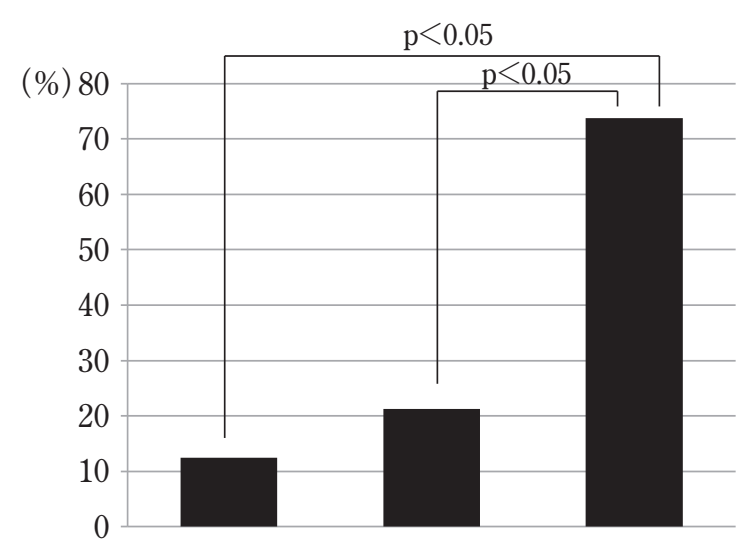

$\sim 20 \mathrm{mmHg} \quad 21 \sim 39 \mathrm{mmHg} \quad 40 \mathrm{mmHg} \sim$

Fig. 5 Mortality rate depends on the maximum ICP value during the measurement period

脳室ドレナージは，頭蓋内コンプライアンスの低下し た状態では, わずかな髄液の排液のみで頭蓋内圧は急激 に低下するため有用である ${ }^{9)}$.

さらには，バルビッレート療法や脳低温療法を用い る。ただし，いずれも多施設研究にて患者予後の改善を 認める報告はない3)13).

最終的には, 減圧開頭術を行う。内科的治療にて頭蓋 内圧六進の改善がみられない場合に選択される。近年, びまん性脳損傷の頭蓋内圧充進症例を対象に多施設研究 が行われたが, 減圧開頭術にて患者予後の改善は得られ なかった4).

このたび，P2009 のデータから，頭蓋内圧立進に対す る治療頻度と転帰について, ICP $(+)$ 群と ICP $(-)$ 群 の 2 群間にて比較検討した. 鎮静や抗痓攣薬, 高浸透圧 利尿剂などの薬物療法は, ICP $(+)$ 群/ICP $(-)$ 群の それぞれで $93.8 \% / 60.7 \%$ で施行されていた（Fig. 6)。過 換気療法は，それぞれ $13.1 \% / 7.6 \%$ ，脳室ドレナージは $25.9 \% / 2.3 \%$ ，体温管理は $68.5 \% / 24.3 \%$ で施行されてお り（Fig. 6)，いずれも ICP $(+)$ 群にて有意に高かった. つまり, ICP $(+)$ 群で, 頭蓋内圧を指標に積極的に頭 蓋内圧充進に対する治療を行っていた。転州良好率は, ICP (+) 群で $29.2 \%$, ICP (-) 群で $30.0 \%$ と 2 群間で 差は認めなかったが(Fig. 7)，mortalityはそれぞれ $32.5 \%$ と 45.0\%で, ICP (+) 群のほうが有意に低かった（Fig. 7)。これらの治療法は，転帰良好率を改善するに至らな かったが, mortalityは有意に減少させており, 今後の頭 部外傷治療における breakthrough が期待されるところで ある。 

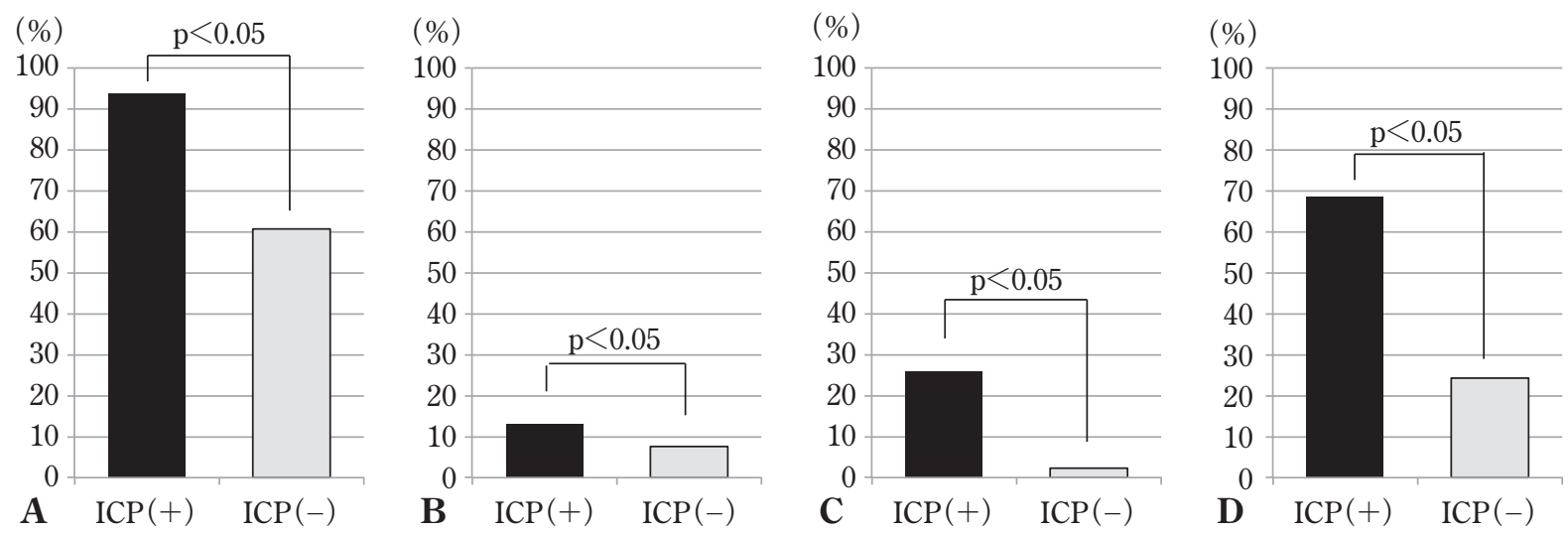

Fig. 6 The performance rate of the medical treatments with ICP monitor use or not
A : Drug treatments.
B : Hyperventilation therapy.
C : Ventricle drainage.
D : Temperature management.
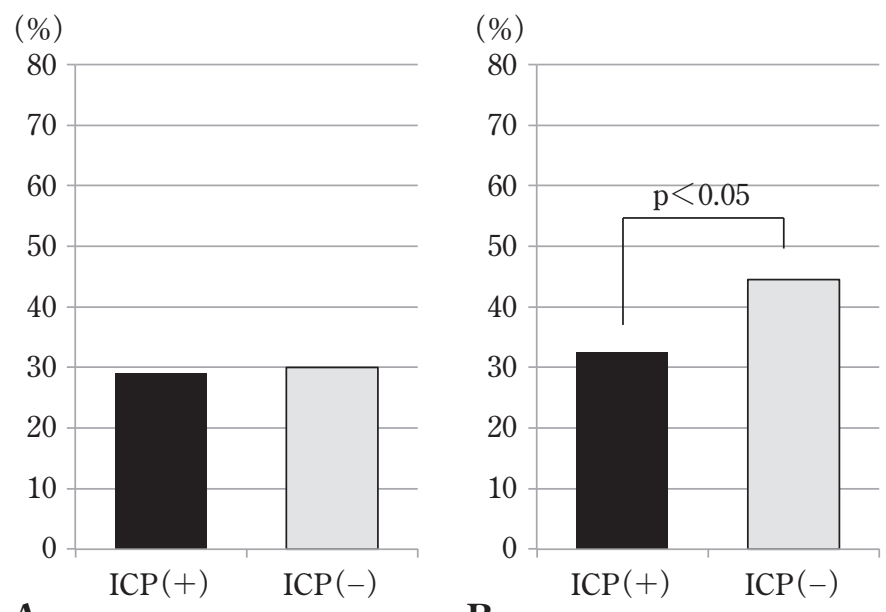

Fig. 7 Favorable outcome rate (A) and mortality rate (B) depend on ICP monitor use

\section{脳神経外科医と救急医 : モニタリングの違い}

頭蓋内圧モニターの利点は, ほかのモニターの併用に より，脳灌流圧や脳の酸素化が維持できるような全身管 理がベッドサイドで可能になること，ならびに，頭蓋内 で何か変化が生じたときにアラームを発してくれる，見 張り番的な役割を果たしてくれることにある。脳神経外 科医と救急医（神経集中治療医）では, 頭部外傷治療に おける役割が異なるため，双方が頭蓋内圧モニターに期 待する点は，必ずしも同じとはかぎらないが，互いの治 療方針を理解し合い, チーム医療として一元的に治療を 行うことが重要である。
すべての著者は，本研究に関して開示すべきCOI はありま せん.

\section{文 献}

1) Brain Trauma Foundation ; American Association of Neurological Surgeons ; Congress of Neurological Surgeons: Guidelines for the management of severe traumatic brain injury. J Neurotrauma 24 Suppl: S1-S106, 2007.

2) Chambers IR, Treadwell L, Mendelow $\mathrm{AD}:$ Determination of threshold levels of cerebral perfusion pressure and intracranial pressure in severe head injury by using receiveroperating characteristic curves : an observational study in 291 patients. J Neurosurg $\mathbf{9 4}: 412-416,2001$. 
3) Clifton GL, Miller ER, Choi SC, Levin HS, McCauley S, Smith KR Jr, Muizelaar JP, Wagner FC Jr, Marion DW, Luerssen TG, Chesnut RM, Schwartz M : Lack of effect of induction of hypothermia after acute brain injury. $N$ Engl $J$ Med 344: 556-563, 2001.

4) Cooper DJ, Rosenfeld JV, Murray L, Arabi YM, Davies AR, D’Urso P, Kossmann T, Ponsford J, Seppelt I, Reilly P, Wolfe $\mathrm{R}$; DECRA Trial Investigators ; Australian and New Zealand Intensive Care Society Clinical Trials Group: Decompressive craniectomy in diffuse traumatic brain injury. $N$ Eng $J$ Med 364: 1493-1502, 2011.

5) Juul N, Morris GF, Marshall SB, Marshall LF : Intracranial hypertension and cerebral perfusion pressure : influence on neurological deterioration and outcome in severe head injury. The Executive Committee of the International Selfotel Trial.J Neurosurg 92:1-6, 2000.

6）亀山元信，刈部 博，小沼武英，冨永悌二：宮城頭部外 傷研究会多施設共同登録調査：年齢と受傷原因・病態・ 転帰。神経外傷 31:49-56, 2008.

7）亀山元信, 刈部 博, 川瀬 誠, 林 俊哲, 平野孝幸, 富永悌二：重症頭部外傷の年齢構成はどのように変化し てきたのか? : 頭部外傷データバンク【プロジェクト 1998，2004，2009】の推移. 神経外傷 36:10-16, 2013.

8) Kelly DF, Goodale DB, Williams J, Herr DL, Chappell ET, Rosner MJ, Jacobson J, Levy ML, Croce MA, Maniker AH, Fulda GJ, Lovett JV, Mohan O, Narayan RK : Propofol in the treatment of moderate and severe head injury: a randomized, prospective double-blinded pilot trial. J Neurosurg 90 : 1042-1052, 1999.

9) Kerr EM, Marion D, Sereika MS, Weber BB, Orndoff AP, Henker R, Wilberger J : The effect of cerebrospinal fluid drainage on cerebral perfusion in traumatic brain injured adults. J Neurosurg Anesthesiol 12:324-333, 2000.

10）日本脳神経外科学会, 日本脳神経外傷学会編：重症頭部 外傷治療・管理のガイドライン，第 3 版。東京，医学書 院，2013.

11) Lobato RD, Sarabia R, Cordobes F, Rivas JJ, Adrados A, Cabrera A, Gomez P, Madera A, Lamas E : Posttraumatic cerebral hemispheric swelling analysis of 55 cases studied with computerized tomography. J Neurosurg $\quad 68: 417-423$, 1988.

12）高村政志, 丸林 徹, 三原洋祐, 新田雅之, 小林 修, 植村正三郎，矢野辰志，大久保勝美，中山俊郎，曽山直 宏，三浦正毅，三股 力，吉田顕正，大塚忠弘，北野郁 夫，藤岡正導，不破 功，山口俊朗，恒成茂行，生塩之 敬：熊本県頭部外傷データバンクこれ迄の成果とこれ からの課題。神経外傷 21：118-124, 1998.

13) Ward JD, Becker DP, Miller JD, Choi SC, Marmarou A, Wood C, Newlon PG, Keenan R : Failure of prophylactic barbiturate coma in the treatment of severe head injury. J Neurosurg $62: 383-388,1985$.

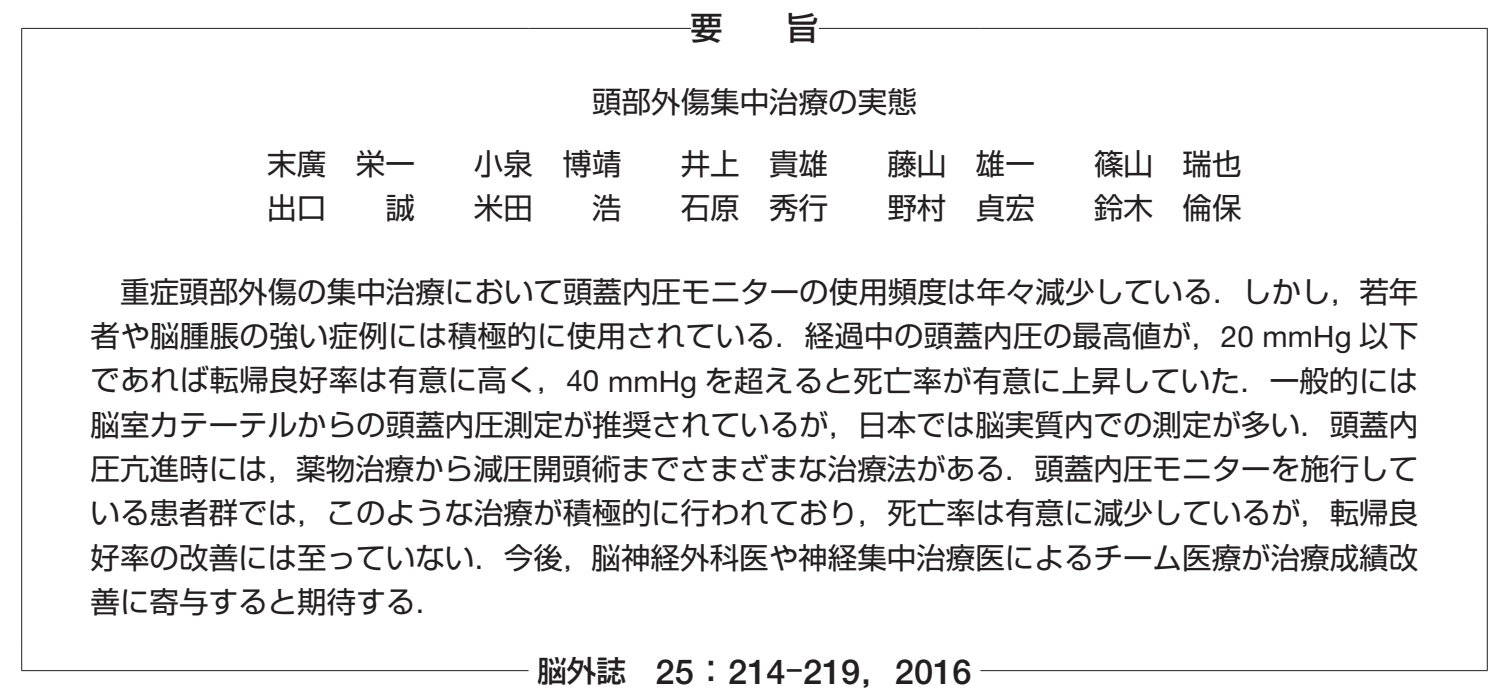

